\title{
LINEAR REGRESSION MODELS FOR LEFT VENTRICULAR MASS BY ECHOCARDIOGRAPHY IN NORMAL IRAQI SUBJECTS
}

\author{
Ramaq Ghassan Wahbi Al-Kadi \\ Medical Physics Unit, Department of Physiology, College of Medicine, \\ Baghdad University.
}

\begin{abstract}
Left ventricular mass (LVM) is an independent risk factor for cardiovascular outcome. M-mode echocardiography, the most commonly used technique for estimation of LVM. The purpose of this study is to establish the regression models for prediction of LVM, measure the normal values of the LVM in normal Iraqi subjects and to compare them with values obtained in Europe, American and Arab people.
\end{abstract}

Keyword: left ventricular mass (LVM), Relative Wall thickness (RWT), Echocardiography, Left ventricular mass index (LVMI).

\section{Introduction}

It is well known that increased left ventricular mass (LVM) is an independent risk factor for cardiovascular morbidity and mortality $(1,2,3)$. Regression of the LVM index has been found to be associated with lower rates of clinical cardiovascular events (4). Several authors suggest that it may be a useful parameter in risk stratification and guiding treatment, especially for hypertensive patients at low or medium risk $(5,6)$. For these reasons, accurate estimation of LVM has crucial importance.

Echocardiography is the most commonly used technique for the estimation of LVM (7, 8,9 , and 10). Devereux et al $(11,12)$ proposed a formula for estimation of LVM and found that the LVM calculated by this formula was consistent with the necropsy data. Calculation of LVM by this formula requires some geometric assumptions. Also, it is found good correlation between echocardiography LVM and true anatomic LVM (11).

The relation between race-ethnicity and LVM has not been fully explored (13). Blacks are more likely to have increased LVM than whites $(14,15)$. While the values of LVM in Arab people are not significantly different from that obtained in Europe and North America (16).

To the best of our knowledge, prediction models for left ventricular mass have not been established in Iraqi people. This study aimed to establishing linear regression models, and to develop normal data for LVM based on age, sex, body weight, height, and body surface area to look if these data are significantly different from their estimated values by $\mathrm{M}$ mode echocardiography method for blacks, whites and Arab-people.

\section{Materials and Method}

A total of one hundred Iraqi subjects were studied in Baghdad- teaching hospital/ Eachocardiography unit between the january2009 to April-2009. One hundred normal subjects were recruited as 50 males and 50 females. Their ages ranged from 19 years to 70 years with mean ages \pm standard deviations of $46.46 \pm 15.73$ and $43.96 \pm 15.44$ for men and women respectively. Any subject with evidence of heart disease, hypertension or other systemic disease was excluded. Examination included measurements of blood pressure, height, weight, body surface area (BSA), and body mass index (BMI). The body mass index (BMI) was calculated as $(\mathrm{BMI}=$ weight/height) (17). Body surface area (BSA) was calculated by: [BSA in $\left(\mathrm{m}^{2}\right)=0.0001 * 71.84$ (weight in $\mathrm{Kg}$ ) 0.425 (Height in $\mathrm{cm}$ )* 0.725] (18).

Echocardiography was performed with Philips ultrasound system with a $3 \mathrm{MHz}$ transducer and measurements were taken by standard two-dimensional (2-D) protocol according to the guidelines of the American Society of Echocardiography (ASE) (19). Posterior wall thicknesses (PWT) in diastole, Septal Wall thickness (SWT) in diastole and end diastolic diameter (EDD) were measured 
in all subjects. Relative wall thickness (RWT) was calculated as the ratio of 2 [posterior wall thickness / end diastolic diameter] (17).

Left ventricular mass was calculated according to the formula published by Devereux and Reichek (11): LVM $=1.04$ $\left[(\mathrm{SWT}+\mathrm{LVID}+\mathrm{PWT})^{3}-(\mathrm{LVID})^{3}\right]-13.6$. LVM was then indexed to body size by dividing raw LVM by height to allometric power of 2.7 and analyzed as a continuous variable $(20,21)$.

\section{Data Analysis}

Pearson's correlation coefficients were derived relating indexed and un-indexed values of LVM measured by M-mode echocardiography and measures body size, weight, height, and body surface area. LVM was also correlated to age. Means \pm SD were calculated for continuous variables. Linear regression models for continuous variables were performed. Statistical significance was determined at the $\alpha=0.05$ level using two sided-tests. Statistical analyses were conducted using WINKS SDA-statistical Data Analysis Version 6.0.5 computer software.

\section{Results}

One hundred Iraqi subjects were enrolled in this study. Equal numbers of men and women enrolled into the study (fifty each) were healthy and free of any medical disease Subjects ages ranged from 19 to 70 years with mean age \pm SD of $46.46 \pm 15.73$ and $43.96 \pm$ 15.44 in men and women, respectively. The characteristics of the study subjects are summarized in Table (1).

\section{Table (1)}

Descriptive statistics of cardiac parameters in 100 healthy subjects (males and females).

\begin{tabular}{|l||c||}
\hline \multicolumn{1}{|c||}{ N=100 } & Mean \pm SD \\
\hline \hline Age (years) & $38.64 \pm 12.38$ \\
\hline Weight $(\mathrm{Kg})$ & $70.97 \pm 8.12$ \\
\hline \hline Height (m) & $1.66 \pm 0.067$ \\
\hline \hline Body Mass Index (BMI) Kg/m ${ }^{2}$ & $25.6 \pm 1.84$ \\
\hline Body surface area (BSA) ${ }^{2}$ & $1.791 \pm 0.133$ \\
\hline \hline LVM (gm) & $165.94 \pm 49.39$ \\
\hline \hline LVM (gm) for [ male ] & $181.79 \pm 53.28$ \\
\hline LVM (gm) for [Female] & $150.07 \pm 39.69$ \\
\hline \hline Systolic BloodPressure[mmHg] & $125.9 \pm 7.9$ \\
\hline \hline DiastolicBloodPressure[mmHg] & $79.2 \pm 8.13$ \\
\hline \hline Relative Wall Thickness(RWT) & $0.32 \pm 0.077$ \\
\hline \hline
\end{tabular}

Table (2)

linear regression equations $\left(R^{2}\right)$ and Their $P$-values between $L V M$, and $R W T$ with age, weight and BSA.

\begin{tabular}{|l||c||c||c||}
\hline Linear regression equation & $\begin{array}{c}\text { P- } \\
\text { value }\end{array}$ & $\mathbf{R}^{2} \mathbf{)}$ & \\
\hline \hline $\mathrm{LVM}=204.45-0.996 *$ Age & 0.012 & 0.623 & $\mathrm{~S}$ \\
\hline \hline $\mathrm{LVM}=74.12+1.294 *$ weight & 0.045 & 0.045 & $\mathrm{~S}$ \\
\hline $\mathrm{LVM}=-218.82+231.26 *$ Height & 0.001 & 0.100 & $\mathrm{~S}$ \\
\hline \hline $\mathrm{LVM}=-6.041+96.03 * \mathrm{BSA}$ & 0.010 & 0.664 & $\mathrm{~S}$ \\
\hline \hline $\begin{array}{c}\mathrm{LVM}=185.79-1.021 * \text { Age }+ \\
0.77 \mathrm{BMI}\end{array}$ & 0.042 & 0.063 & $\mathrm{~S}$ \\
\hline \hline $\mathrm{RWT}=0.372-0.0014 *$ Age & 0.025 & 0.050 & $\mathrm{~S}$ \\
\hline \hline $\mathrm{RWT}=-0.154+0.283 *$ Height & 0.013 & 0.061 & $\mathrm{~S}$ \\
\hline $\begin{array}{c}\mathrm{LVM} / \mathrm{BSA}=11.159-0.478 * \\
\text { Age }\end{array}$ & 0.024 & 0.050 & $\mathrm{~S}$ \\
\hline
\end{tabular}

$S=$ Significant.

Table (3)

Pearson's correlation coefficients (r) and P-values between all the anthropometric variables in normal subjects.

\begin{tabular}{|c|c|c|c|c|c|}
\hline $\begin{array}{c}\text { Cardiac } \\
\text { parameters }\end{array}$ & Age (Years) & Height (m) & Weight (Kg) & BMI $\left(\mathrm{Kg} / \mathrm{m}^{2}\right)$ & BSA $\left(\mathrm{m}^{2}\right)$ \\
\hline LVM (gm) & $\begin{array}{c}\mathrm{r}=-0.249 \\
\mathrm{P}=0.012 \\
(\mathrm{~S})\end{array}$ & $\begin{array}{c}\mathrm{r}=0.317 \\
\mathrm{P}=0.001 \\
(\mathrm{~S})\end{array}$ & $\begin{array}{c}\mathrm{r}=0.213 \\
\mathrm{P}=0.034 \\
(\mathrm{~S})\end{array}$ & $\begin{array}{c}\mathrm{r}=-0.027 \\
\mathrm{P}=0.79 \\
(\mathrm{NS})\end{array}$ & $\begin{array}{c}\mathrm{r}=0.258 \\
\mathrm{P}=0.01 \\
(\mathrm{~S})\end{array}$ \\
\hline LVM/Height ${ }^{2.7}$ & $\begin{array}{c}\mathrm{r}=-0.172 \\
\mathrm{P}=0.087 \\
(\mathrm{NS})\end{array}$ & $\begin{array}{c}\mathrm{r}=0.057 \\
\mathrm{P}=0.574 \\
(\mathrm{NS})\end{array}$ & $\begin{array}{c}\mathrm{r}=-0.086 \\
\mathrm{P}=0.395 \\
(\mathrm{NS})\end{array}$ & $\begin{array}{c}\mathrm{r}=-0.077 \\
\mathrm{P}=0.444 \\
(\mathrm{NS})\end{array}$ & $\begin{array}{c}\mathrm{r}=-0.087 \\
\mathrm{P}=0.389 \\
(\mathrm{NS})\end{array}$ \\
\hline LVM/BSA & $\begin{array}{c}\mathrm{r}=-0.225 \\
\mathrm{P}=0.024(\mathrm{~S})\end{array}$ & $\begin{array}{c}\mathrm{r}=0.0915 \\
\mathrm{P}=0.365 \\
(\mathrm{NS})\end{array}$ & $\begin{array}{c}\mathrm{r}=-0.036 \\
\mathrm{P}=0.716 \\
(\mathrm{NS})\end{array}$ & $\begin{array}{c}\mathrm{r}=-0.167 \\
\mathrm{P}=0.095 \\
(\mathrm{NS})\end{array}$ & $\begin{array}{c}\mathrm{r}=0.0034 \\
\mathrm{P}=0.973 \\
(\mathrm{NS})\end{array}$ \\
\hline RWT & $\begin{array}{c}\mathrm{r}=-0.224 \\
\mathrm{P}=0.025(\mathrm{~S})\end{array}$ & $\begin{array}{c}\mathrm{r}=0.248 \\
\mathrm{P}=0.013(\mathrm{~S})\end{array}$ & $\begin{array}{c}\mathrm{r}=0.146 \\
\mathrm{P}=0.147 \\
(\mathrm{NS})\end{array}$ & $\begin{array}{c}\mathrm{r}=-0.060 \\
\mathrm{P}=0.551 \\
(\mathrm{NS})\end{array}$ & $\begin{array}{c}\mathrm{r}=0.196 \\
\mathrm{P}=0.051 \\
(\mathrm{NS})\end{array}$ \\
\hline
\end{tabular}

[ $r$ = correlation coefficient,$S=$ Significant,$N S=$ Not significant ] 
The values of LVM were correlated to age, weight, height and body surface area in one hundred normal subjects as shown in Figs. (1, 2, 3, 4).

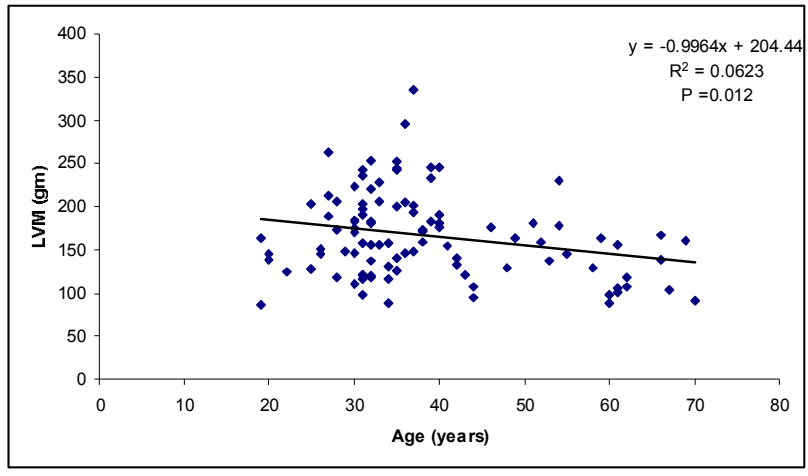

Fig.(1) : Left Ventricular Mass (LVM) by Echocardiography against age.

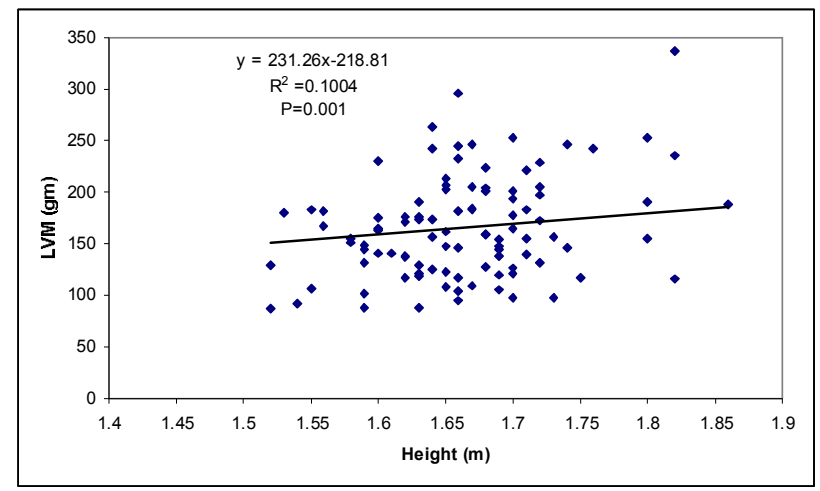

Fig.(2): Left ventricular mass (LVM) by echocardiography against height.

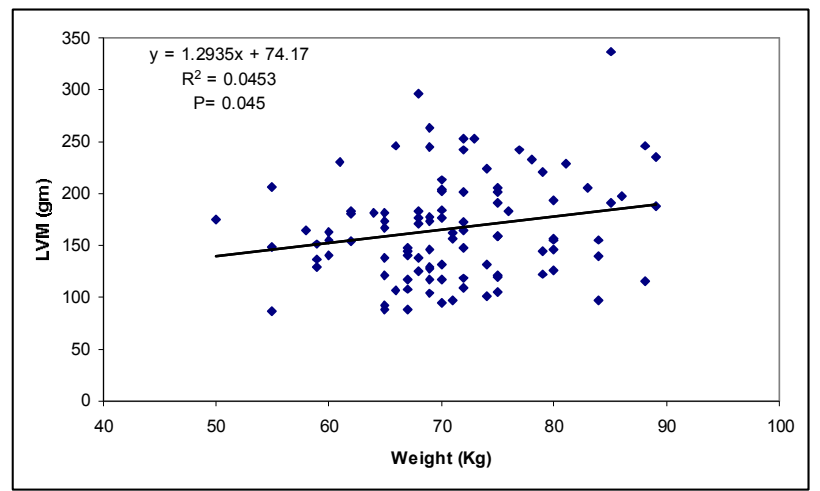

Fig.(3): Left ventricular mass (LVM) by Echocardiography against weight.

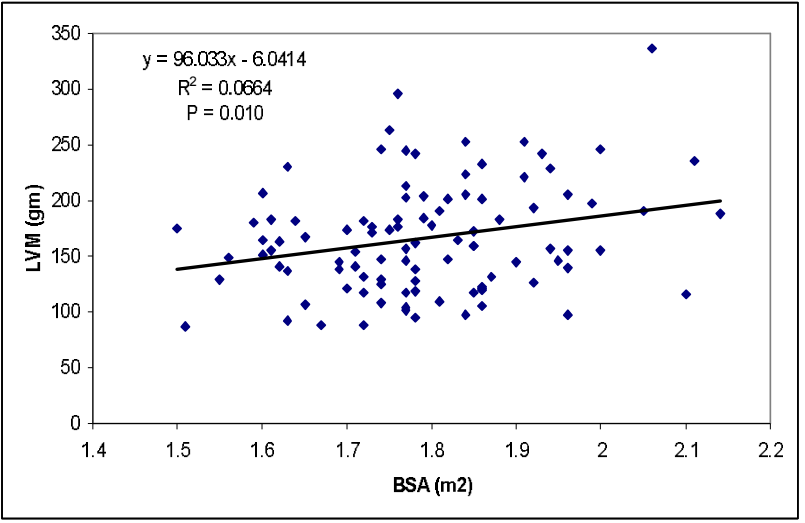

Fig.(4): Left Ventricular Mass (LVM) by Echocardiography against Body Surface Area (BSA).

Our data showed significant linear relationship between LVM with weight $(\mathrm{P}<0.05)$, height $(\mathrm{P}<0.05)$ and body surface area $(\mathrm{P}<0.05)$. Age was significantly related to LVM $(\mathrm{P}<0.05)$. No significant correlation were noted between the LVM-indexed to height $^{2.7}\left(\mathrm{LVM} / \mathrm{Height}^{2.7}\right)$ with age $(\mathrm{P}>0.05)$, weight $(\mathrm{P}>0.05)$, and body surface area (BSA) $\mathrm{P}>0.05$. Also the LVM-indexed to body surface area (LVM/BSA) was significantly correlated with age $(\mathrm{P}<0.05)$. The results clearly pointed the significant relation between the relative wall thickness (RWT) with age $(\mathrm{P}<0.05)$ and height $(\mathrm{p}<0.05)$, Fig.s (5) and (6).

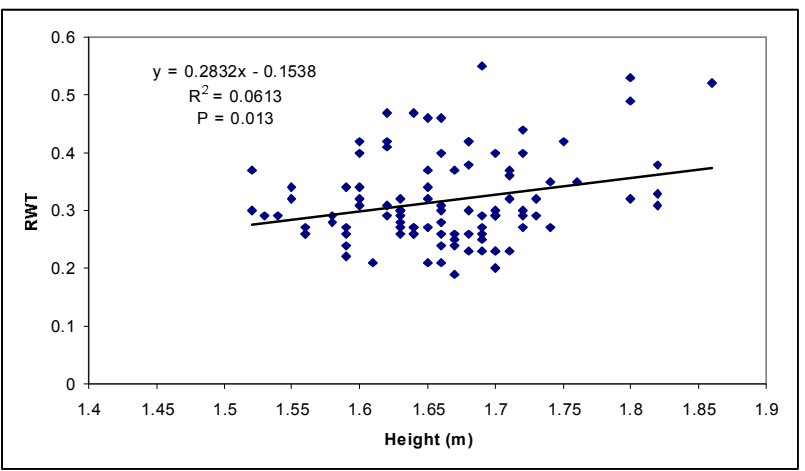

Fig.(5): Relative Wall Thickness (RWT) against the height. 


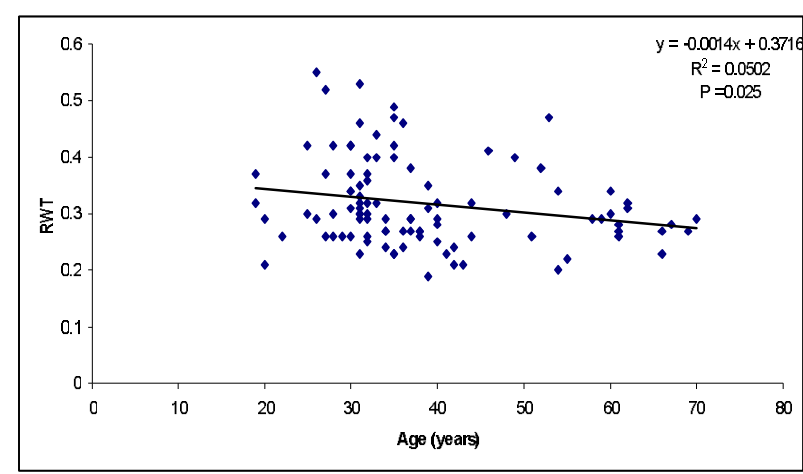

Fig.(6): Relative Wall Thickness against the age.

\section{Discussion}

The present study demonstrates that in subjects free of clinically overt cardiovascular disease, the value of LVM among Iraqi subjects was $181.8 \mathrm{gm}$ for male and $150.1 \mathrm{gm}$ for female. Compared with results of other studies, the LVM in male was $180 \mathrm{gm}$ as measured by echocardiogram (22). While the study in a multi-ethnic Southeast Asian population reported that the LVM in men and women were $189 \mathrm{gm}$ and $148 \mathrm{gm}$ respectively (23). One study in west population indicated that small sample of both male and female together; the LVM was 163 gm (24), which similar with our findings. However, other studies in west population found that LVM was $173 \mathrm{gm}$ for men and $114 \mathrm{gm}$ for women (25), and $156 \mathrm{gm}$ for men and $116 \mathrm{gm}$ for women (26). The present study is partly confirms the findings of other study in Arab people which reported that the LVM was $186.9 \mathrm{gm}$ for men and $168.3 \mathrm{gm}$ for women (16).These difference values of LVM may be due to measurements of left ventricle end diastolic diameter by $\mathrm{M}$-mode echocardiography. Because the third power of left ventricular internal diameter (LVID) in the LVM-formula, change in the LVID alone may cause an erroneous estimation in LVM (27).

In this study, age was a good robust predictor of LVM and RWT. Studies were reported that LVM was significantly related to age in women only, but it was significantly associated with height in both male and female in white people $(22,28)$. While in Arab people, LVM was correlated to age in women, but not in men (16). Some authors $(29,30)$ have observed that age significantly affects left ventricular structure and geometric patterns.
The attenuation of the age-LVM relation in healthy subjects of Framingham study (28) suggests that LVM increases with age not by virtue of an intrinsic myocardial aging process, but rather as a function of extra-myocardial events that accompany advancing age. Almost all Framingham study participants are white; therefore their results may not applicable to non-white individuals. In addition variation in LVM may be explained in part by variables not assessed in those studies such as genetic, neurohormonal and endocrine factors.

The methods of correcting LVM for body size have varied between studies. LVM has been adjusted for height, body surface area, weight, and height rose to various powers. Height $^{2.7}$ (in meters) has been valided as an indicator of lean body mass and has been recommended for indexing $\operatorname{LVM}(20,21)$. Use of Height ${ }^{2.7}$ to index LVM also minimizes the effect of age, gender, and race $(20,31)$. Other studies demonstrated that LVM-indexed to height (LVM/Height) reduces variation to the body size and sex (16, 24). In the present study; There were no relation between the $\mathrm{LVM} / \mathrm{Height}^{2.7}$ with age $(\mathrm{P}>0.05)$, whereas a significant negative correlation between (LVM/BSA) with age, $(r=-0.224, P=0.025)$ Table-3. Similar to our findings, one study found that the LVM/Height in Arab people was not significant related with age (16). Mean while, other studies were reported that (LVM/BSA) was significant related with age in Southeast Asian population (23), while in white individuals the (LVM/BSA) was not relation of age to LVM.

Relative wall thickness (RWT) has the strongest correlation with blood pressure in hypertensive subjects (31). In this study a linear regression equations of RWT shows a significant correlation between RWT with age $\mathrm{P}<0.05$ and height $\mathrm{P}<0.05$. No relation was observed between the RWT with body surface area (BSA) $\mathrm{P}>0.05$. These results are not in agreed with other studies in African American population $(31,32)$. Studies comparing the left ventricular structure and function among black and white subjects had suggested that RWT and LVM are higher in blacks (33). This observation could have attenuated the age related changes in Left ventricular geometric 
patterns that have been observed in Caucasians (34). On other hand, patients with a normal clinic blood pressure may show abnormalities on ambulatory blood pressure monitoring. This phenomenon of "masked hypertension" may have more clinical relevance because ambulatory blood pressure has a stronger impact than damage and cardiovascular outcomes (15).

Although standardized methods have been proposed for echocardiography, they are not uniformly followed. This could explain the wide variation in the results, in addition to different ways of analysis and also different ways of correlation between the measured values of LVM with different parameters of the body including size, height, weight, age, and body surface area. On the top of all these factors, any parameter obtained from white populations is not necessarily applicable to the non-white people.

\section{Conclusion}

Despite these problems, this study offers valuable information about the LVM in Iraqi subjects;

1.This study established prediction formulas for normal LVM and RWT both of which would be useful in the assessment of cardiomyopathies.

2.Our data for LVM values in healthy Iraqi subjects (age range 19-70 years), are not significantly different from that found in other countries, especially in Arab people.

3.Also in this study demonstrated potentially relation of age, weight, height and body surface area to LVM.

\section{References}

[1] Levy D, Garrison RJ, Savage DD, Kannel WB, CastelliWP.Prognostic implications of Echocardiographically determined left Ventricular mass in the Framingham Heart Study.N Engl J Med.1990; 322:1561-6.

[2] Schillaci G, Verdecchia P, Porcellati C, Cuccurullo O, Casco C, Perticone F. Continuous relation between left ventricular mass and cardiovascular risk in essential hypertension. Hypertension 2000; 35:580-6.
[3] Casale PN. Devereux RB, Milner, et al. Value of echocardiographic measurement of left ventricular mass in predicting cardiovascular morbid events in hypertensive men. Ann Intern Med 1986; $105 ; 173-8$.

[4] Devereux RB, Wachtell K, Gerdts E, et al. Prognostic significance of left ventricular mass change during treatment of hypertension. JAMA 2004: 292:2350-6.

[5] European Society of HypertensionEuropean Society of Cardiology Guidelines Committee. 2003 European Society of Hypertension-European Society of Cardiology Guidelines for the management of arterial hypertension. J Hypertens 2003; 21: 1011-53.

[6] Schillaci G, De Simone G, Reboldi G, Porcellati C, Devereux RB, Verdecehia P. Change in cardiovascular risk profile by echocardiography in low-or medium-risk hypertension. J Hypertens 2002; 20: 1519 25.

[7] Gopal A.S., Schnellbaecher M.J., Shen Z., Akinboboye O.O., Sapin P.M., King D.L. Freehand three dimensional echocardiography for measurement of left ventricular mass: in vivo anatomic validation using explanted human hearts. J Am Coll Cardiol (1997) 30:802-810. [Abstract].

[8] Bellenger N.G., Marcus N.J., Davies C., Yacoub M., Banner N.R., Penell D.J. Left ventricular function and mass after orthotropic heart transplantation: a comparison of cardiovascular magnetic resonance with echocardiography. J Heart Lung Transplant (2000) 19: 444425. [midline].

[9] Missouris C.G., Forbat S.M., Singer D.R., Markandu N.D., Underwood R; Mac Gregor G.A. Echocardiography overestimates left ventricular mass: a comparative study with magnetic resonance imaging in patients with hypertension. J Hypertens (1996) 14: 1005-1010.

[10] Steward G.A, Foster J., Cowan M., et al. Echocardiography overestimates left ventricular mass in hemodialysis patients relative to magnetic resonance imaging. Kidney Int (1999) 56: 2248-2253. 
[11] Devereux RB, Reichek N. Echocardiographic determination of left ventricular mass in man. Anatomic validation of the method. Circulation 1977; 55: 613-8.

[12] Devereux RB, Alonso DR, Lutas EM,et al. Echocardiographic assessment of left ventricular hypertrophy: Comparison to necroscopy findings. Am J Cardiol 1986 : $57: 450-8$.

[13] Carlos J. Rodriguez, Sciacca RR, DiezRoux A, Albala BB, Sacco RL, Homma S, DiTullio M. Relation between Socioeconomic status, Race-Ethnicity, and left ventricular mass: The Northern Manhattan Study . Hypertension.2004:775779.

[14] Liao Y, Cooper RS, McGee DL, Mensah GA, Ghali JK. The relative effects of left ventricular hypertrophy, coronary artery disease, and ventricular dysfunction on survival among Black adults. JAMA.1995:273:1592-1597.[pub Med].

[15] El-Gharbawy AH, Kotchen JM, Grim CE, Kaldunski M, Hoffmann RG, Pausova Z, Gaudet D, Gossard F, Hamet P, Kotchen TA. Predictors of target organ damage in hypertensive blacks and white. Hypertension.2001； 38: 761-766.[pub Med].

[16] Mohammad M.J. Determination of left ventricular mass by Echocardiography in normal Arab people. Medical Journal of Islamic Academy of Sciences. 2001, 14:2, 61-66.

[17] Muscholl MW, Hense H, Brockel U, Doring A, Riegger GAJ, Scunkert H . Changes in left ventricular structure and function in patients with white coat hypertension: Cross sectional survey. BMJ (1998) 317:565-570.

[18] Dubois EP: Basal Metabolism in health and disease. Philadelphia. Lea and Febiger, 1936.

[19] Sahn DJ, Demaria A, Kisslo J, Wayman A: The committee on M-mode Standaization of the American Society of Echocardiography: recommendation regarding quantitation in M-mode echocardiography:results of a survey of echocardiographic measurements. Circulation (1978), 58: 1072.
[20] de Simon G, Daniels SR, Devereux RB, Meyer RA, Roman MJ, de Divitiis O, Alderman MH. Left ventricular mass and body size in normotensive children and adults: assessment of allometric relations and impact of overweight. J Am Coll Cardiol. 1992; 20; 1251-1260. [pub Med].

[21] Zalbalgoitia M, Rahman SN, Haley WE, Oneschuk, Yunis C, Lucas C, Yarows S, Krausa L, Amerena J. Impact of ethnicity on left ventricular mass and relative wall thickness in essential hypertension. Am J Cardiol. 1998: 81: 412-417.

[22] Fagard R, Staessen J, Thijis L, Amery A: Relation of left ventricular mass and filling to exercise blood pressure and rest blood pressure. Am J Cardiol, 1995: 75: 53.

[23] Raymond Ching, James Wei-Luen Yip, Anuj Gupta, Lieng $\mathrm{H}$ Ling. Echocardiographic Left ventricular mass in a multiethnic Southeast Asian Population: proposed new Gender and Age-specific norms. Echocardiography: 2008, (25): 805811.

[24] Chuang ML, Danias PG, Riley MF, Hibberd MG, Manning WJ, Douglas P: Effect in increase body mass index on accuracy of two-dimensional echocardiography for measurement of left ventricular volume, ejection fraction and mass. Am J Cardiol, (2001) 87: 371.

[25] Lauer MS, Anderson KM, Larson MG, Levy D: A new method for indexing left ventricular mass for differences in body size. Am J Cardiol, 1994: 74: 487.

[26] Gardin JM, Siscovick D, Hoda AC, Lynch JC, Smith VE, Kloptenstein HS, Bommer WJ, Fried L, O Leary D, Manolio TA: Sex age and disease affect echocardiographic left ventricular mass and systolic function in the free-living elderly: The cardiovascular health study. Circulation 1995,91: 1739.

[27] M Kilickap, S Turhan, T Sayin, et al. Intravascular volume dependency of left ventricular mass calculation by two dimensional guided M-mode echocardiography. Can J Cardiol 2007; 23 (3):219 -222.

[28] Levy D, Savage DD, Garrison RJ, Anderson KM, Kannel WB, Castelli WP: Echocardiographic criteria for left 
ventricular hypertrophy. The Framingham heart study. Am J Cardiol, 1987: 59: 956.

[29] Shipilova T, Pshenichnikov I, Kailk J, Volozh O, Abina J, Kalev M, Lass J, Meigas K. Echocardiographic assessment of the different left ventricular geometric patterns in middle-aged men and women in Tallinn. Blood Press. 2003; 12: 284-290.

[30] de Simone G, Daniels SR, Kimball TR, Roman MJ, Romano C, Chinali M, Galderisi M, Devereux RB. Evaluation of concentric left ventricular geometry in humans: evidence for age-related systematic underestimation. Hypertension 2005: 45: 64-68.

[31] Ugwu,A.C., Okwar,C.A., Amaechi AJ. Evaluation of left ventricular structures in normotensive and hypertensive subjects by two-dimensional echocardiography: Anthropometric correlates in hypertension. Internet journal of medical Update. 2008 Vol.(3), No.2.

[32] Okwor,C.A, Ugwu,A.C, Eze,J. Linear regression models for quantitative assessment of left ventricular function and structures using M-mode echocardiography. African Journal of Biotechnology. 2008, Vol.7 (13), 21122115.

[33] Hinderliter AL. Blumenthal JA. Waugh R, Chilukuri M, Sherwood A. Ethnic differences in left ventricular structure: relations to hemodynamics and diurnal blood pressure variation. American Journal of Hypertension: 2004: 17:49.

[34] Akinyemi Aje, Adewole A, Olulola O, Adekola D, Okechukwu S.O, Dike B.O, Ayodele O.F. Left ventricular geometric patterns in newly presenting Nigerian hypertensive: An Echocardiographic study. BMC Cardiovasc Disord: 2006; 6: 2261-6.
تعتبر تقنية تخطيط صدى القلب بواسطة ألأمواج فوق

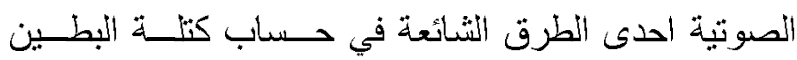

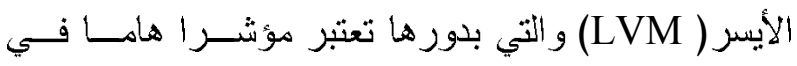

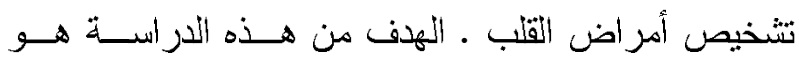

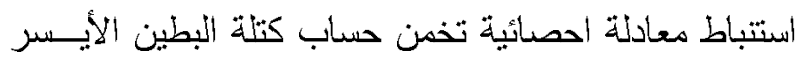

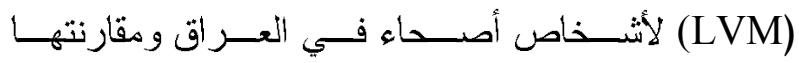

بالأثخاص الأصحاء في كل من أوروبا ،أمريكا والــوطن العربي. 